Check for updates

Cite this: RSC Adv., 2019, 9, 21207

Received 23rd April 2019

Accepted 2nd July 2019

DOI: 10.1039/c9ra03004b

rsc.li/rsc-advances

\section{Performance and selectivity of lower-rim substituted calix[4]arene as a stationary phase for capillary gas chromatography $\dagger$}

\author{
Tao Sun, (D) *a Bin Li, ${ }^{b}$ Xiaomin Shuai, ${ }^{c}$ Yujie Chen, ${ }^{a}$ WeiWei Li, ${ }^{a}$ Zhiqiang Cai, ${ }^{\text {*c }}$ \\ Xiaoguang Qiao, ad Shaoqiang $\mathrm{Hu}^{\mathrm{a}}$ and Lufang $\mathrm{Ma}$ (D)
}

\begin{abstract}
This work presents the investigation of p-tert-butyl(tetradecyloxy)calix[4]arene (C4A-C10) as stationary phase for capillary gas chromatographic (GC) separations. The statically-coated C4A-C10 capillary column showed weak polarity and column efficiency of 2566 plates per $m$ determined by $n$-dodecane at $120{ }^{\circ} \mathrm{C}$. Impressively, the C4A-C10 column exhibited extremely high resolving capability for a wide range of analytes from nonpolar to polar, including $n$-alkanes, esters, ketones, aldehydes, alcohols and bromoalkanes. Most importantly, the C4A-C10 column exhibited an excellent separation performance for positional, structural and cis-/trans-isomers. Among them, the column displayed advantageous resolving capability over the commercial polysiloxane stationary phase for aromatic amine isomers. Moreover, the C4A-C10 column showed good column repeatability with RSD values below $0.06 \%$ for run-to-run, $0.12-0.27 \%$ for day-to-day and $2.8-5.3 \%$ for column-to-column.
\end{abstract}

\section{Introduction}

Macrocyclic compounds (crown ethers, cyclodextrins, calixarenes and cucurbiturils) have unique configuration characteristics, such as different cavity size, conformation, and functionality, allow the formation of host-guest interactions between hosts and numerous guests, and result in widely varying applications in supramolecular chemistry, coordination chemistry, and separation science. ${ }^{1-5}$ In chromatographic separation, macrocyclic compounds have been reported as adsorption materials for sample preparation and as stationary phases for liquid chromatography (LC), gas chromatography (GC) and capillary electrochromatography (CEC).$^{6-10}$ Calixarenes, the third generation of host supramolecules following crown ethers and cyclodextrins, were obtained by the oligomerization of para-substituted phenol and formaldehyde. ${ }^{\mathbf{1 1}}$ The calixarenes hosts have attracted much attention in

${ }^{a}$ College of Chemistry and Chemical Engineering, Henan Key Laboratory of Function-Oriented Porous Materials, Luoyang Normal University, Luoyang 471934, P. R. China. E-mail: suntao2226@163.com

${ }^{b}$ Hebei Key Laboratory of Heterocyclic Compounds, Handan University, Handan 056005, China

${ }^{c}$ School of Petrochemical Engineering, Shenyang University of Technology, Liaoyang, 111003, Liaoning, P. R. China. E-mail: kahongzqc@163.com

${ }^{d}$ Henan Joint International Research Laboratory of Living Polymerizations and Functional Nanomaterials, Henan Key Laboratory of Advanced Nylon Materials and Application, School of Material Science and Engineering, Zhengzhou University, Zhengzhou, 450001, P. R. China

$\dagger$ Electronic supplementary information (ESI) available. See DOI: 10.1039/c9ra03004b supramolecular chemistry and molecular recognition. ${ }^{\mathbf{1 2}}$ The calixarenes endowed with characteristic 3D-shaped cavities provide a useful platform for designing new functionalized host molecules which render a variety of binding sites for recognition of anions, cations and neutral molecules. ${ }^{13-15}$ By taking advantage of the introduction of functional groups into the lower and upper rims, a wide variety of chemically modified calixarenes has been synthesized with a number of selective factors. ${ }^{16-18}$ Calixarenes hosts possess unique features such as 3D cavities, construction and substituents, which offer highly selective interaction sites with guest molecules via $\pi-\pi$, dipoledipole, H-bonding, and van der Waals interactions. ${ }^{19}$ In addition, calixarenes have favorable thermal stability and chemical stability, their upper rim and lower rim are easy to be derivatized, and substituent groups have a great bearing on the physicochemical properties of calixarenes and host-guest interactions. $^{20}$

Capillary gas chromatography (GC) has been attached with great importance by workers occupied in analytical chemistry by virtue of its high separation efficiency, fast analysis speed and high sensitivity and has been extensively applied in various fields such as environmental analysis, food analysis, pharmaceutical analysis and petrochemical industry. ${ }^{21-24}$ In GC, the stationary phase of special selectivity is the key for components, which are to be determined, to realize high-efficiency separation. In recent decades, calixarenes have received increasing attention for their exploitation as GC stationary phases due to their unique structures and physicochemical properties. ${ }^{25-28}$ Mangia and coworkers firstly reported separation of alcohols, chlorinated hydrocarbons, and aromatic compounds by gas- 

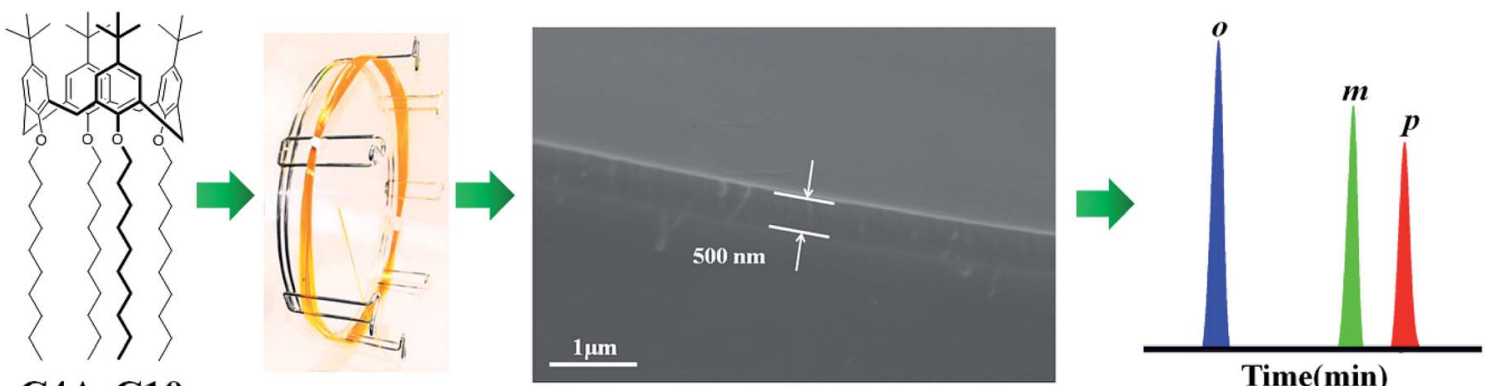

\section{C4A-C10}

Scheme 1 The C4A-C10 capillary column for GC separation.

solid chromatography with $p$-tert-butylcalix[8]arene absorbed on Chromosorb W..$^{29}$ However, it's difficult to coat unsubstituted calixarenes on the inner wall of the capillary column due to its high melting point and poor film-forming ability, which restricts its application as stationary phase for GC. Subsequently, the derivatized calixarenes and physically blended calixarene/polysiloxane have been utilized as stationary phases in GC separations. Zhang et al. has developed the mixed mode stationary phase based on calixacrown grafted polysiloxanes, which has been successfully used for the separation of aromatic isomers in GC. ${ }^{30} \mathrm{Yu}$ et al. reported the mixture of calix[4]arene and OV-1701 as stationary phase in the gas chromatograph, successfully separated alcohols, halohydrocarbons and aromatic compounds and found that tert-butyl on the upper rim of calix[4]arene played a significant role in the recognition process of solute molecules. ${ }^{31}$ Delahousse et al. used calix[6]arene derivative as stationary phase through the sol-gel method for GC separation of PCBs and PAHs. ${ }^{28}$

As illustrated in Scheme 1, we presents the investigation of utilizing the $p$-tert-butyl(tetradecyloxy)calix[4]arene (C4A-C10) stationary phase for GC separations. Compared with mixedmode stationary phases, C4A-C10 stationary phase can reflect retention behaviors and interaction mechanisms of calixarene-type stationary phases more directly. The modification of backbone structure by introducing of functional units is an effective strategy for improving the separation performance of the modified stationary phases..$^{32,33}$ In this work, nonpolar long alkyl chains groups were introduced at the lower rim of the calixarenes, which can increase their column efficiency based on the improving solubility and film- forming ability of the stationary phase. First, the C4A-C10 capillary column was fabricated by static coating method and characterized for its column efficiency and polarity. Then, it was investigated for its separation performance and retention behaviours by employing the different analytes of great variety, including nonpolar ( $n$-alkanes), low to medium polar (esters, aldehydes, ketones), polar analytes (alcohols, bromoalkanes), substituted benzenes, and the positional, structural and cis-/trans-isomers. Meanwhile, one commercial HP-5 column (5\% phenyl 95\% dimethyl polysiloxane) was employed for reference. Afterwards, the column repeatability of C4A-C10 column was evaluated in terms of run-to-run, day-to-day and column-to-column.

\section{Experimental}

\subsection{Materials and equipment}

All the reagents and solvents employed were commercially available and were used as received without further purification. All the analytes were of analytical grade and dissolved in dichloromethane. Table S1 in ESI $\dagger$ provides the chemical structures of the analytes. Untreated fused-silica capillary tubing $(0.25 \mathrm{~mm}$, i.d.) was purchased from Yongnian Ruifeng Chromatogram Apparatus Co., Ltd. (Hebei, China). A commercial HP-5 capillary column $(30 \mathrm{~m} \times 0.25 \mathrm{~mm}$, i.d., $0.25 \mu \mathrm{m}$ film thickness, $5 \%$ phenyl $95 \%$ dimethyl polysiloxane) was purchased from Agilent Technologies Co. Ltd. (Palo Alto, USA) and used as the reference column.

An Agilent 7890A gas chromatograph equipped with a split/ splitless injector, a flame ionization detector (FID) and an
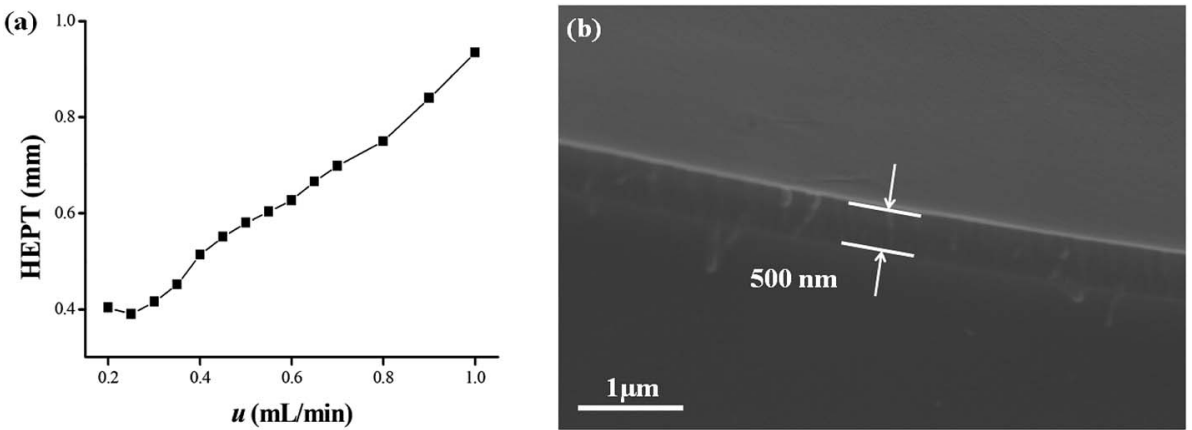

Fig. 1 (a) Golay curves of the C4A-C10 capillary column determined by $n$-dodecane at $120^{\circ} \mathrm{C}$ and (b) the cross-section SEM images on the inner wall surface and the coating thickness of the C4A-C10 capillary column. 
Table 1 McReynolds constants of the C4A-C10 and commercial column $^{a}$

\section{Stationary}

$\begin{array}{llllllll}\text { phases } & \mathrm{X}^{\prime} & \mathrm{Y}^{\prime} & \mathrm{Z}^{\prime} & \mathrm{U}^{\prime} & \mathrm{S}^{\prime} & \text { General polarity Average }\end{array}$

\begin{tabular}{llllllll}
\hline C4A-C10 & 86 & 140 & 78 & 148 & 158 & 610 & 122
\end{tabular}

$\begin{array}{llllllll}\text { HP-5 } & 30 & 72 & 62 & 96 & 65 & 325 & 65\end{array}$

${ }^{a} \mathrm{X}^{\prime}$, benzene; $\mathrm{Y}^{\prime}$, 1-butanol; $\mathrm{Z}^{\prime}$, 2-pentanone; $\mathrm{U}^{\prime}$, 1-nitropropane; $\mathrm{S}^{\prime}$, pyridine. Temperature: $120{ }^{\circ} \mathrm{C}$.

autosampler was used for GC separations. All the separations were performed under the following GC conditions: nitrogen of high purity $(99.999 \%)$ as carrier gas, injection port at $300^{\circ} \mathrm{C}$, split ratio at $60: 1$, FID detector at $300^{\circ} \mathrm{C}$. Oven temperature programs for the GC separations were individually provided in their figure captions. ${ }^{1} \mathrm{H}$ NMR spectra were recorded on a Bruker Biospin 400 MHz instrument using TMS as the internal standard. All chemical shifts were reported in ppm. IR spectra were recorded on a Bruker Platinum ART Tensor II FT-IR spectrometer. MALDITOF-MS was recorded on a Bruker BIFLEX III mass spectrometer. Scanning electron microscopy (SEM) images were recorded on a Zeiss Sigma 500 microscope (Zeiss, Germany).

\subsection{Synthesis of the C4A-C10 stationary phase}

C4A-C10 was synthesized according to ref. 34 and 35 para tertiary butyl phenol $(5.0 \mathrm{~g}, 0.03 \mathrm{~mol})$ was dissolved in $40 \%$ formaldehyde solution ( $30 \mathrm{~mL}, 0.04 \mathrm{~mol})$, sodium hydroxide $(0.06 \mathrm{~g}, 1.5 \mathrm{mmol})$ was added. The mixture was stirred at $120^{\circ} \mathrm{C}$ for $2 \mathrm{~h}$ and diphenyl ether $(50 \mathrm{~mL})$ was added dropwise. After stirring for $5 \mathrm{~h}$ at the same temperature, the mixture was cooled to room temperature and ethyl acetate $(50 \mathrm{~mL})$ was added. There was a large amount of precipitation. After filtration, white solid was obtained. The white solid (1.5 g, $2.3 \mathrm{mmol}$ ) and 60\% sodium hydrogen $(1.0 \mathrm{~g}, 25 \mathrm{mmol})$ were dissolved in anhydrous DMF (15 mL). The mixture was stirred at room temperature for $0.5 \mathrm{~h}$ and $n-\mathrm{C}_{10} \mathrm{H}_{21} \mathrm{Br}(20 \mathrm{~mL})$ was added. The solution was heated to $85{ }^{\circ} \mathrm{C}$ for $6 \mathrm{~h}$. White precipitate begins to precipitate out. The excess sodium hydrogen was decomposed by water and methanol. Solid $(2.1 \mathrm{~g}, 1.74 \mathrm{mmol})$ is obtained by filtering, ${ }^{1} \mathrm{H}$ NMR $\left(\mathrm{CDCl}_{3}, 400 \mathrm{MHz}\right): \delta 6.90(\mathrm{~s}, 8 \mathrm{H}), 4.05(\mathrm{~s}, 8 \mathrm{H}), 3.57(\mathrm{~s}, 8 \mathrm{H})$, 1.66 (s, 8H), 1.27 (s, 56H), 1.04 (s, 36H), 0.92-0.86 (m, 12H); IR $\left(\mathrm{KBr}, \mathrm{cm}^{-1}\right)$ : 2954(C-H), 2921(C-H), 2852(C-H), 1481(C=C), $1466(\mathrm{C}=\mathrm{C}), 1209(\mathrm{C}-\mathrm{O}-\mathrm{C}), 1191(\mathrm{C}-\mathrm{O}-\mathrm{C}), 1113(\mathrm{C}-\mathrm{O}-\mathrm{C}), 1003(\mathrm{C}-$ O-C), 883(C-H), 721(C-H); MALDI-TOF MS: $\mathrm{m} / \mathrm{z}$ calcd for $\mathrm{C}_{84} \mathrm{H}_{136} \mathrm{O}_{4}: 1209.0$ (100\%); found: $2456.0[2 \mathrm{M}+\mathrm{K}-\mathrm{H}]^{+}(100 \%)$.
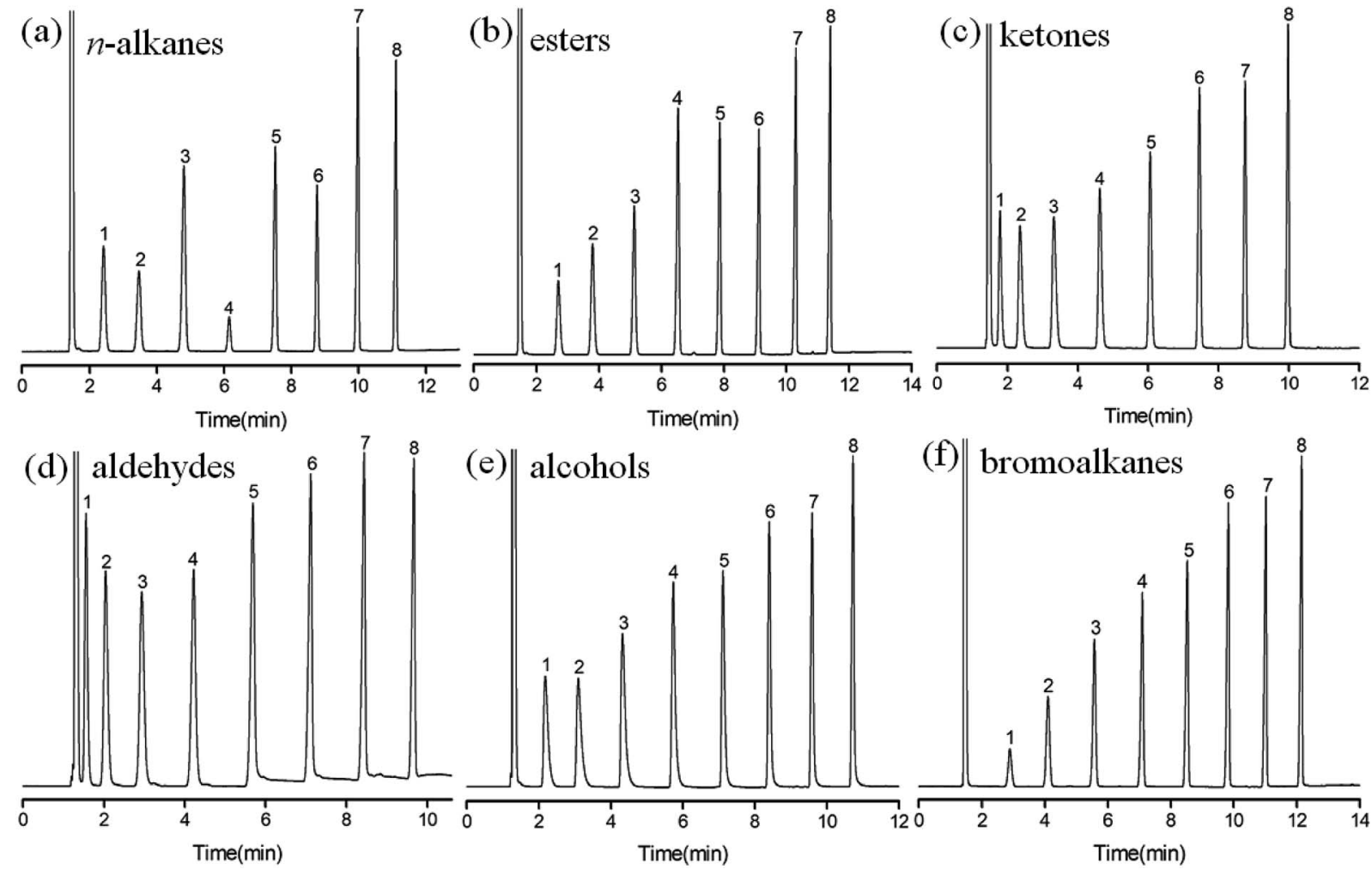

Fig. 2 GC separation of (a) $n$-alkanes, (b) esters, (c) ketones, (d) aldehydes, (e) alcohols and (f) bromoalkanes on C4A-C10 column. Peaks for (a): (1) $n$-hexane, (2) $n$-heptane, (3) $n$-octane, (4) n-nonane, (5) $n$-decane, (6) $n$-undecane, (7) $n$-dodecane, (8) $n$-tridecane; peaks for (b): (1) methyl valerate, (2) methyl hexanoate, (3) methyl heptanoate, (4) methyl octanoate, (5) methyl nonanoate, (6) methyl decanoate, (7) methyl undecanoate, (8) methyl dodecanoate; peaks for (c): (1) 2-pentanone, (2) 2-hexanone, (3) 2-heptanone, (4) 2-octanone, (5) 2-nonanone, (6) 2-decanone, (7) 2-undecanone, (8) 2-dodecanone; peaks for (d): (1) valeraldehyde, (2) hexaldehyde, (3) heptaldehyde, (4) octanal, (5) nonanal, (6) decanal, (7) undecanal, (8) dodecanal; peaks for (e): (1) 1-pentanol, (2) 1-hexanol, (3) 1-heptanol, (4) 1-octanol, (5) 1-nonanol, (6) 1-decanol, (7) 1undecanol, (8) 1-dodecanol; peaks for (f): (1) 1-bromopentane, (2) 1-bromohexane, (3) 1-bromoheptane, (4) 1-bromooctane, (5) 1-bromononane, (6) 1-bromodecane, (7) 1-bromoundecane, (8) 1-bromododecane. Temperature program for (a-f): $40{ }^{\circ} \mathrm{C}$ for 1 min to $160{ }^{\circ} \mathrm{C}$ at $10{ }^{\circ} \mathrm{C} \mathrm{min}^{-1}$, flow rate at $0.6 \mathrm{~mL} \mathrm{~min}^{-1}$. 


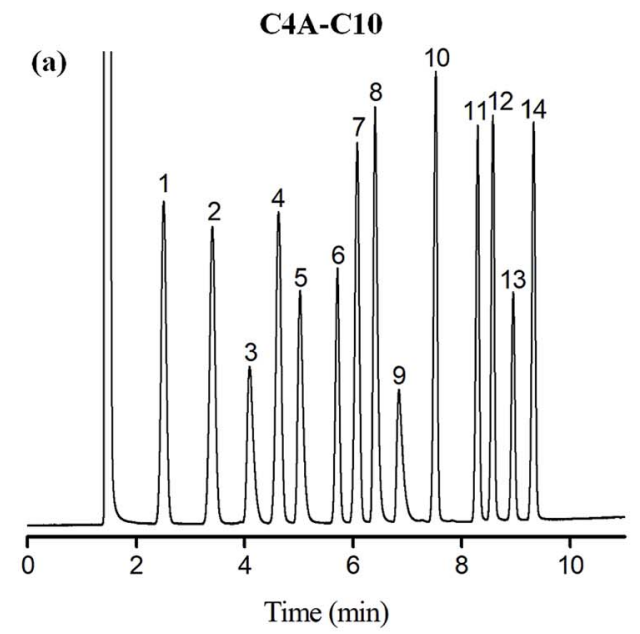

C4A-C10

(b)

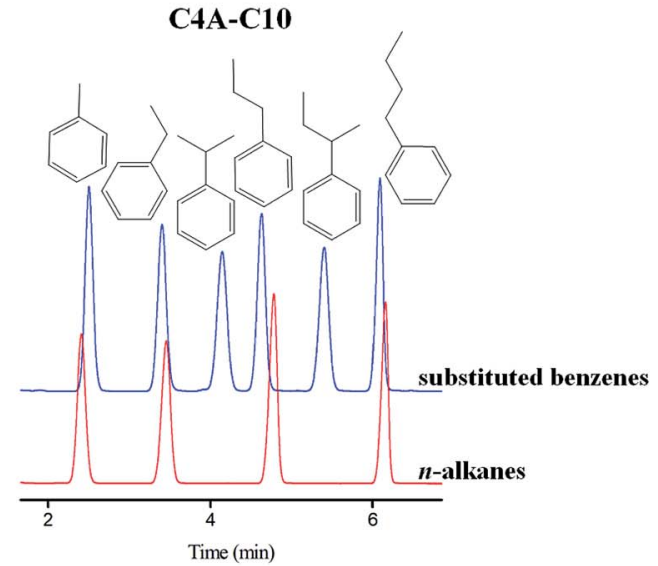

HP-5

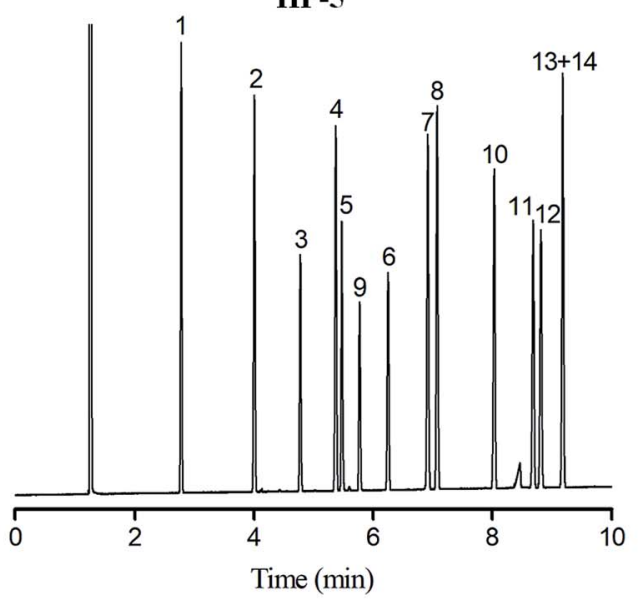

HP-5

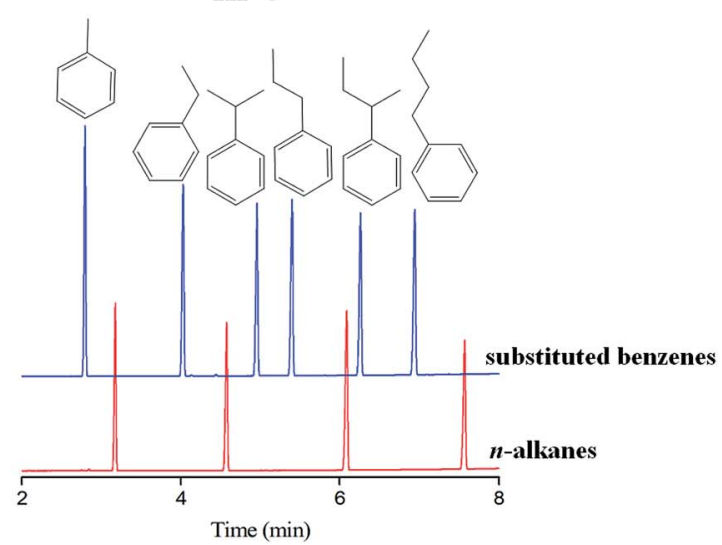

Fig. 3 GC separation of (a) substituted benzenes and (b) benzenes and $n$-alkanes on C4A-C10 column and HP- 5 commercial column (10 $\mathrm{m} \times$ $0.25 \mathrm{~mm}$, i.d.). Peaks for (a): (1) toluene, (2) ethylbenzene, (3) 3,4,5-trichlorobenzaldehyde, (4) propylbenzene, (5) benzaldehyde, (6) 1,4dichlorobenzene, (7) n-butylbenzene, (8) acetophenone, (9) phenol, (10) 1,3-dibromobenzene, (11) 1,3,5-trichlorobenzene, (12) 1,2,4-trichlorobenzene, (13) 1,2,3-trichlorobenzene, (14) 1,2-dibromobenzene; peaks for (b) benzenes: toluene, ethylbenzene, cumene, propylbenzene, sec-butylbenzene, $n$-butylbenzene; peaks for (b) $n$-alkanes: $n$-octane, $n$-nonane, $n$-decane, $n$-undecane. Temperature program for (a) and (b): $40{ }^{\circ} \mathrm{C}$ for $1 \mathrm{~min}$ to $160{ }^{\circ} \mathrm{C}$ at $10^{\circ} \mathrm{C} \mathrm{min}^{-1}$, flow rate at $0.6 \mathrm{~mL} \mathrm{~min}$.

\subsection{Fabrication of the C4A-C10 capillary column}

The C4A-C10 capillary column was fabricated by static coating method. ${ }^{32,36}$ First, a bare fused-silica capillary column $(10 \mathrm{~m} \times$ $0.25 \mathrm{~mm}$, i.d.) was pretreated with a saturated solution of sodium chloride in methanol for its inner surface roughing. Afterwards, the column was conditioned up to $200{ }^{\circ} \mathrm{C}$ and held for $3 \mathrm{~h}$ under nitrogen atmosphere. Then, the pretreated column was statically coated with the solution of the C4A-C10 stationary phase in dichloromethane $(0.25 \%, \mathrm{w} / \mathrm{v})$ at room temperature. After the column was filled with the stationary solution, one end of the column was sealed and the other end was connected to a vacuum system to gradually remove the solvent under vacuum at $40{ }^{\circ} \mathrm{C}$. The coated column was conditioned from $40^{\circ} \mathrm{C}$ held for $30 \mathrm{~min}$ to $160^{\circ} \mathrm{C}$ at $1{ }^{\circ} \mathrm{C} \mathrm{min}{ }^{-1}$ and held at the high-end temperature for $7 \mathrm{~h}$ under nitrogen.

Table 2 The boiling point of benzenes and $n$-alkanes

\begin{tabular}{|c|c|c|c|c|c|}
\hline \multicolumn{3}{|l|}{ Benzenes } & \multicolumn{3}{|l|}{ n-Alkanes } \\
\hline Compound & Molecular formula & $\begin{array}{l}\text { Boiling } \\
\text { point }\end{array}$ & Compound & Molecular formula & $\begin{array}{l}\text { Boiling } \\
\text { point }\end{array}$ \\
\hline Toluene & C7H8 & $111^{\circ} \mathrm{C}$ & n-Octane & C8H18 & $125^{\circ} \mathrm{C}$ \\
\hline Ethylbenzene & $\mathrm{C} 8 \mathrm{H} 10$ & $136^{\circ} \mathrm{C}$ & $n$-Nonane & $\mathrm{C} 9 \mathrm{H} 20$ & $151{ }^{\circ} \mathrm{C}$ \\
\hline Cumene & C9H12 & $152{ }^{\circ} \mathrm{C}$ & $n$-Decane & $\mathrm{C} 10 \mathrm{H} 22$ & $170^{\circ} \mathrm{C}$ \\
\hline Propylbenzene & C9H12 & $159^{\circ} \mathrm{C}$ & $n$-Undecane & $\mathrm{C} 11 \mathrm{H} 24$ & $196{ }^{\circ} \mathrm{C}$ \\
\hline sec-Butylbenzene & $\mathrm{C} 10 \mathrm{H} 14$ & $173^{\circ} \mathrm{C}$ & & & \\
\hline$n$-Butylbenzene & $\mathrm{C} 10 \mathrm{H} 14$ & $183^{\circ} \mathrm{C}$ & & & \\
\hline
\end{tabular}




\section{Results and discussion}

\subsection{Characterization of the C4A-C10 column}

Characteristic parameters of the C4A-C10 column concerning column efficiency and McReynolds constants were determined. ${ }^{37-39}$ As shown in Fig. 1a, the Golay curve relating the heights equivalent to a theoretical plate (HETP) with flow rates were determined by $n$-dodecane at $120{ }^{\circ} \mathrm{C}$, and the minimum HETP of $0.39 \mathrm{~mm}$ was observed at $0.25 \mathrm{~mL} \mathrm{~min}^{-1}$ corresponding to the column efficiency of 2566 plates per m. McReynolds constants were used to characterize the polarity of the C4A-C10 stationary phase by using the five probes of benzene, 1-butanol, 2-pentanone, 1-nitropropane and pyridine at $120^{\circ} \mathrm{C}$. As shown in Table 1, the McReynolds constants of the C4A-C10 stationary phase, suggesting its weak polarity close to that of the HP-5 stationary phase. Hence, the commercial HP-5 column was employed for reference in the following work. Fig. 1b presented the SEM cross-section images of the C4A-C10 column, confirming its good coating with the thickness of approximately $500 \mathrm{~nm}$ on the capillary column.

\subsection{Separation capability and retention behaviours}

Separation performance of the C4A-C10 column was evaluated by GC separation of different analytes of great variety, including nonpolar ( $n$-alkanes), low to medium polar (esters, aldehydes, ketones), polar analytes (alcohols, bromoalkanes), substituted benzenes, and the positional, structural and cis-/trans-isomers.
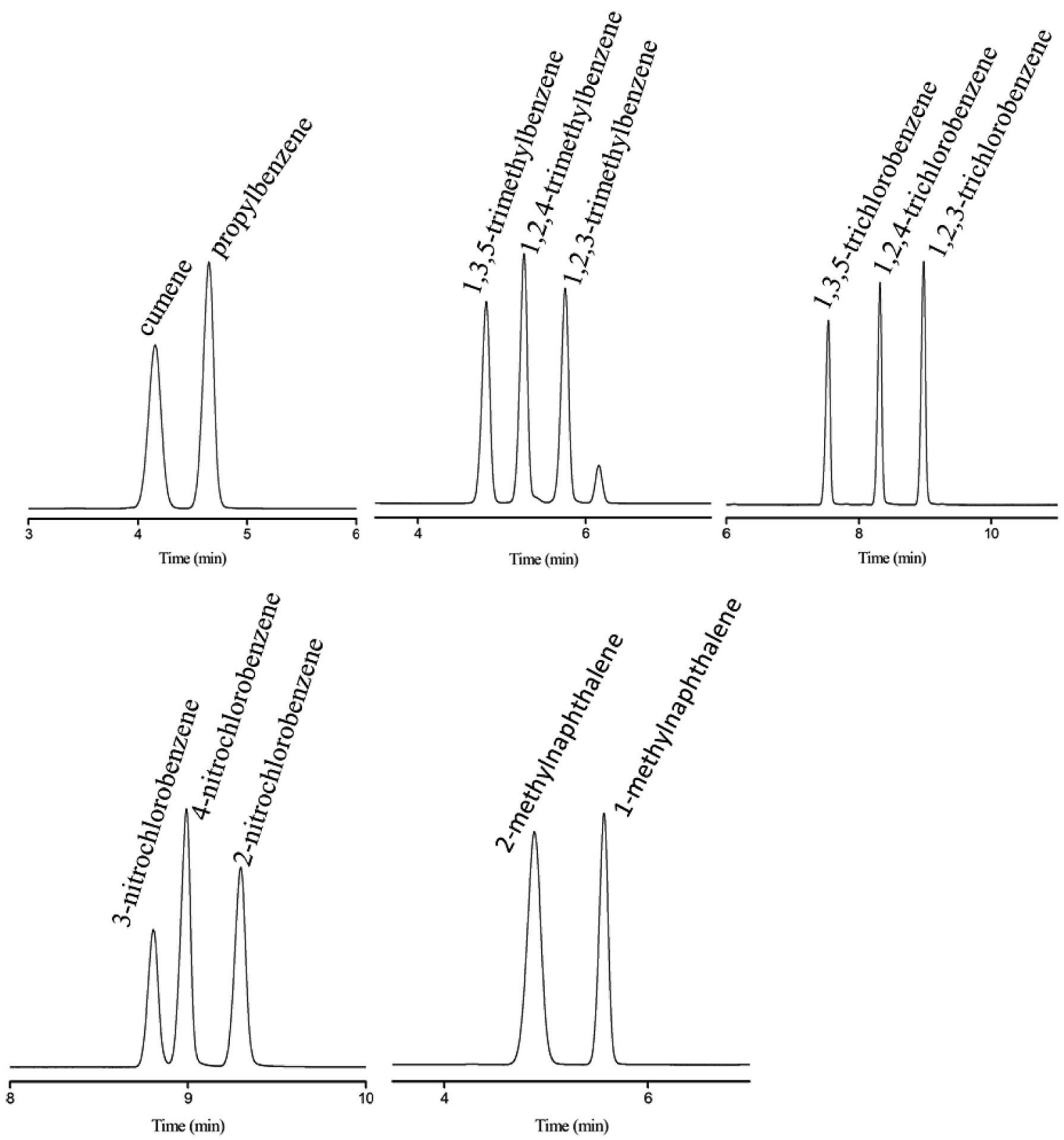

Fig. 4 Separations of isomer mixtures of propylbenzenes, trimethylbenzenes, trichlorobenzenes, nitrochlorobenzene and methylnaphthalenes on C4A-C10 column. Temperature program for benzenes: $40{ }^{\circ} \mathrm{C}$ for $1 \mathrm{~min}$ to $160{ }^{\circ} \mathrm{C}$ at $10{ }^{\circ} \mathrm{C} \mathrm{min}^{-1}$, flow rate at $0.6 \mathrm{~mL} \mathrm{~min}{ }^{-1}$. 
Fig. 2 shows the chromatograms for GC separations of the linear analytes with similar carbon numbers on C4A-C10 column, including the mixtures of $n$-alkanes, esters, ketones, aldehydes, alcohols and bromoalkanes. As results, the C4A-C10 column achieved baseline resolution for all the analytes and exhibited nice peak shapes for both nonpolar and polar analytes. Although the analytes have different polarities, their retention time on the column is within 12 minutes under the same GC conditions. This may be related to the molecular structure of C4A-C10 stationary phase. There are four long linear alkyl chains at the lower rim of C4A-C10, which have similar van der Waals interactions to linear molecules of similar carbon numbers.

The aromatic structure of $\mathrm{C} 4 \mathrm{~A}-\mathrm{C} 10$ is conducive for enhancing $\pi-\pi$ interactions among analytes of the $\pi$-system. Fig. 2a shows the separations of the mixture of substituted benzenes consisting of 14 analytes on the C4A-C10 column in comparison to the HP-5 columns. As shown, the C4A-C10 column achieved baseline resolution $(R>1.5)$ for all the analytes and outperformed the HP-5 column that coeluted the pair of 1,2,3-trichlorobenzene/1,2-dibromobenzene (peaks 13/14). The above results demonstrate the high-resolution performance of the C4A-C10 stationary phase towards the aromatic analytes ranging from nonpolar to polar nature. Moreover, the $\mathrm{C} 4 \mathrm{~A}-\mathrm{C} 10$ column distinctly prolongs the retention of phenol (peak 9). This phenomenon suggests the stronger interactions of the C4A-C10 stationary phase with the benzene with hydroxyl, possibly thanks to the $\pi-\pi$ electron-donor/acceptor (EDA) interactions. In order to further study the influence of the aromatic skeleton of the C4A-C10 stationary phase on its chromatographic retention behavior, we investigate the chromatographic retention behavior of aromatics and alkanes with similar carbon numbers as analytes. Fig. 3b shows the separation of aromatics and $n$-alkanes on the C4A-C10 and HP-5 stationary phases with the same chromatographic separation conditions. As can be seen, toluene (b.p., $\left.111^{\circ} \mathrm{C}\right) / n$-octane (b.p., $125{ }^{\circ} \mathrm{C}$ ), ethylbenzene (b.p., $136{ }^{\circ} \mathrm{C}$ ) $/ n$-nonane (b.p., $151{ }^{\circ} \mathrm{C}$ ), propylbenzene (b.p., $159{ }^{\circ} \mathrm{C}$ ) $/ n$-decane (b.p., $170{ }^{\circ} \mathrm{C}$ ), and $n$ butylbenzene (b.p., $183^{\circ} \mathrm{C}$ ) $/ n$-undecane (b.p., $196{ }^{\circ} \mathrm{C}$ ) (Table 2) have different carbon numbers and boiling points, but they have similar retention times on the C4A-C10 column. Compared to the HP-5 stationary phase with a $\pi$-aromatic system, the C4A-C10 stationary phase exhibits prolonged retention trend for aromatics over alkanes. This interesting finding suggests the stronger molecular interactions of the aromatics with the $\mathrm{C} 4 \mathrm{~A}-\mathrm{C} 10$ stationary phase. The stronger retention for the aromatics can be ascribed to the unique aromatic skeleton of the calix[4] arene stationary phase with the $3 \mathrm{D}$ cavity, which may favor enhancing their $\pi-\pi$ interactions to a large extent. And for aromatics, the $\pi-\pi$ interactions between the calix[4]arene stationary phase and analytes may dominate.

Subsequently, the C4A-C10 column was investigated for its capability to separate positional, structural and cis-/transisomers. Fig. 4 shows the separations of five isomer mixtures
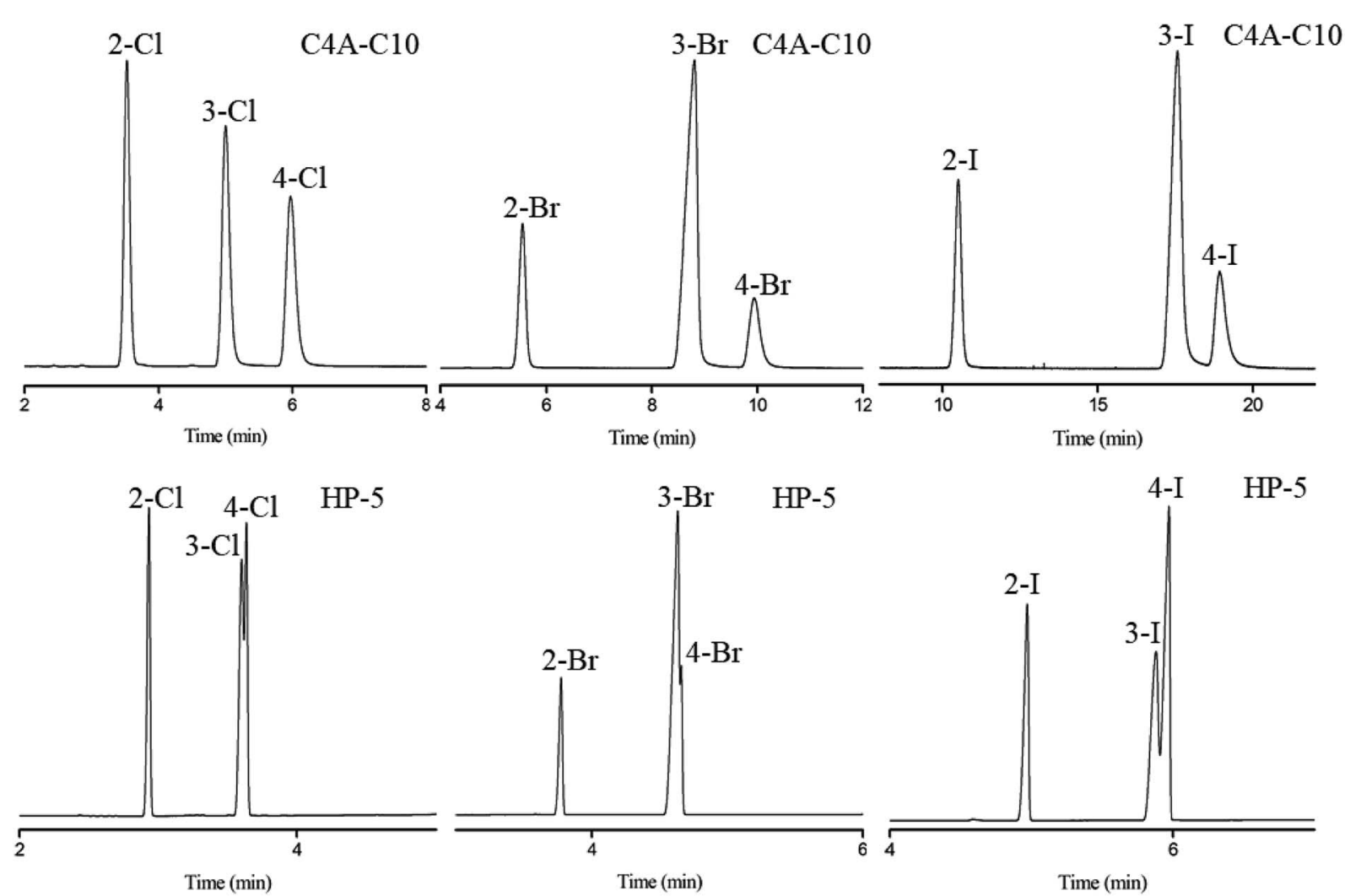

Fig. 5 Separations of aromatic amine isomers on the C4A-C10 column in comparison to the HP- 5 commercial column (30 $\mathrm{m} \times 0.25 \mathrm{~mm}$, i.d.). The GC separation on two columns was performed under same condition. Temperature programs for chloroaniline, bromaniline and iodoaniline: $100{ }^{\circ} \mathrm{C}$ for $1 \mathrm{~min}$ to $160{ }^{\circ} \mathrm{C}$ at $10{ }^{\circ} \mathrm{C} \mathrm{min}-1$, flow rate at $0.6 \mathrm{~mL} \mathrm{~min}{ }^{-1}$. 


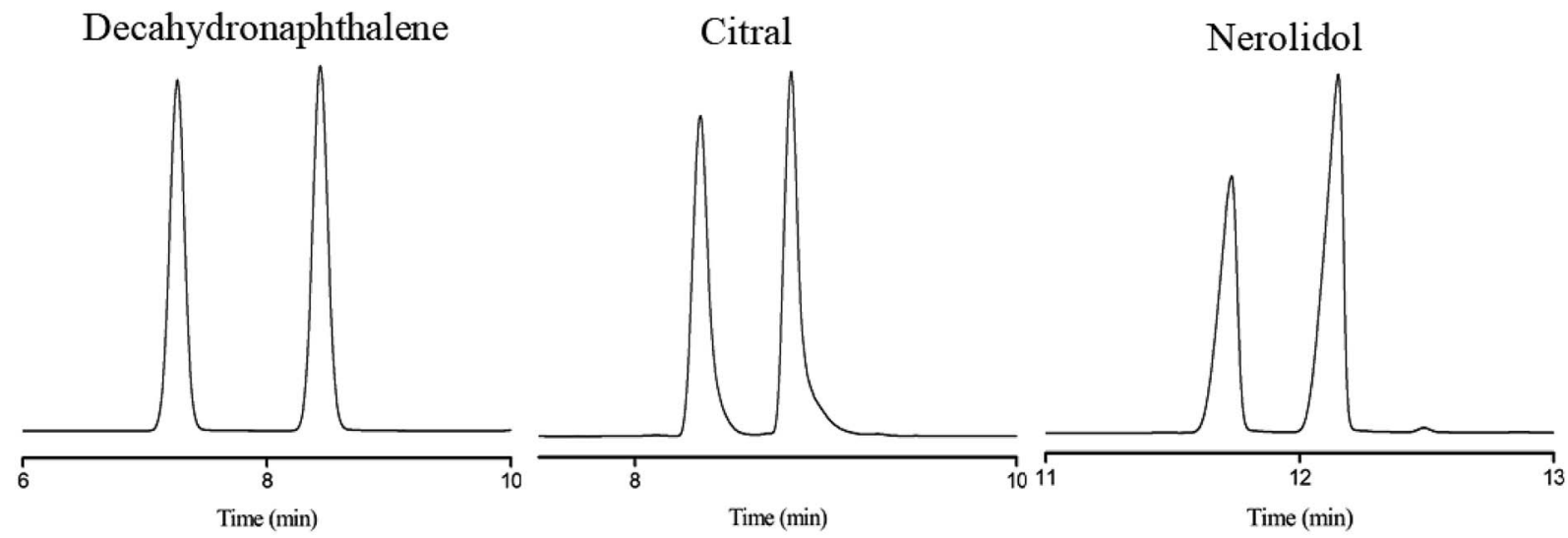

Fig. 6 Separations of cis-/trans-isomers on the C4A-C10 column. Temperature programs for decahydronaphthalene, citral and nerolidol: $40{ }^{\circ} \mathrm{C}$ for $1 \mathrm{~min}$ to $160{ }^{\circ} \mathrm{C}$ at $10^{\circ} \mathrm{C} \mathrm{min}{ }^{-1}$, flow rate at $0.6 \mathrm{~mL} \mathrm{~min}{ }^{-1}$.

Table 3 Repeatability and reproducibility of C4A-C10 column on the retention times ( $t_{R}$, min) of the indicated isomers

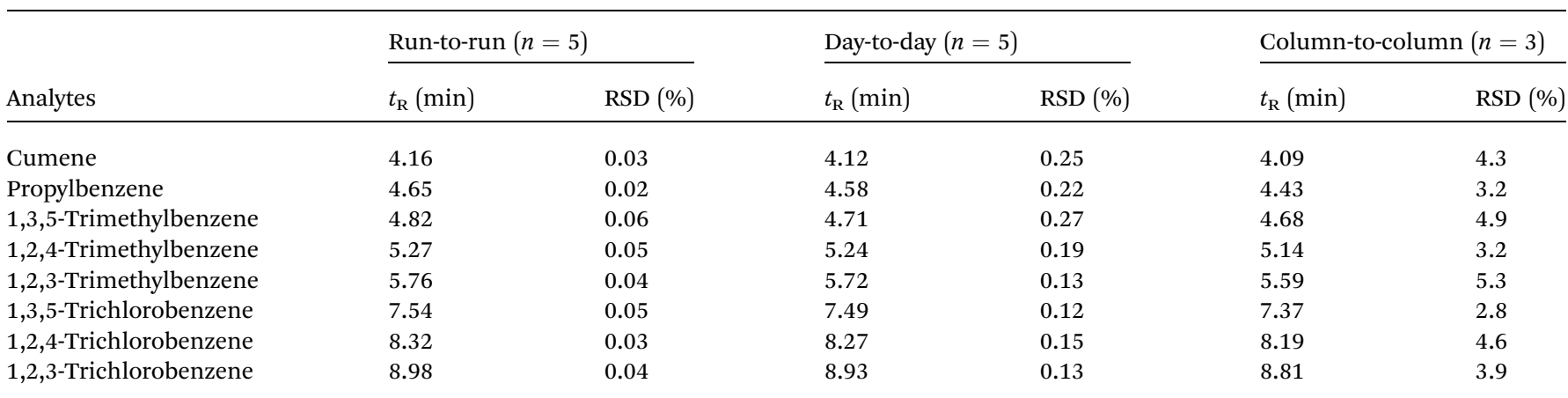

ranging from nonpolar to polar nature on the C4A-C10 column, including propylbenzenes, trimethylbenzenes, trichlorobenzenes, nitrochlorobenzene and methylnaphthalenes. The baseline resolution of the isomer mixtures evidenced its high resolving capability for analytes of close nature. Specifically, the isomer pairs of 2-methylnaphthalene/1methylnaphthalene differ slightly in their boiling points $(<2$ ${ }^{\circ} \mathrm{C}$ ). Efficient separation of aromatic amine isomers is a challenging issue in chemical industry and environmental analysis. To the best of our knowledge, very few stationary phases are available for the separation of aromatic amine isomers, most of which demand complicated and harsh derivatization process before separation by GC-ECD or GC-MS. ${ }^{40-43}$ Therefore, it is still a challenge to find an appropriate stationary phase for the rapid and efficient separation of aromatic amine isomers. Fig. 5 presents the separations of the chloroaniline, bromaniline and iodoaniline isomers on the $\mathrm{C} 4 \mathrm{~A}-\mathrm{C} 10$ stationary phase in comparison to the polysiloxane HP-5 stationary phase with similar polarity. As shown, the C4A-C10 column well resolved all the analytes $(R>1.5)$ and showed advantageous separation capability over the HP-5 commercial column $(30 \mathrm{~m} \times 0.25 \mathrm{~mm}$, i.d.). Notably, some of the analytes partially overlapped or even coeluted on the HP-5 commercial column. Fig. 6 illustrates the separation of three cis-/trans-isomers containing decahydronaphthalene, citral and nerolidol on C4A-C10 column. As shown, it achieved baseline resolution for the aromatic and aliphatic isomers with good peak shapes. The C4A-C10 column achieved high resolution of these isomers due to their $\pi-\pi$ and van der Waals interactions with analytes. The above results for the critical isomers demonstrate the great potential of the C4AC10 column for GC analysis.

\subsection{Column repeatability}

For the fabricated C4A-C10 columns, column repeatability (runto-run, day-to-day) and reproducibility (column-to-column) were investigated by separations of the isomer mixtures of propylbenzenes, trimethylbenzenes and trichlorobenzenes, and evaluated by relative standard deviation (RSD\%) on their retention times. The obtained results are summarized in Table 3 , showing the RSD values of $0.02-0.06 \%$ for run-to-run, $0.12-$ $0.27 \%$ for day-to-day and $2.8-5.3 \%$ for column-to-column, respectively. These results demonstrate its good column repeatability in daily operations and in column preparation.

\section{Conclusion}

This work presents the investigation of the C4A-C10 stationary phase for GC separations. The statically coated C4A-C10 column without any deactivation exhibits good separation performance and column inertness for a wide range of analytes from nonpolar to polar, including those prone to peak tailing in GC analysis such as alcohols and aldehydes. It should be noted that 
the C4A-C10 stationary phase exhibited an excellent separation performance for aromatic amine isomers, showing distinct advantages over the commercial polysiloxane stationary phase. The high selectivity of C4A-C10 stationary phase may stem from their unique structures and host-guest interactions involving $\pi-\pi$ and van der Waals interactions.

\section{Conflicts of interest}

There are no conflicts to declare.

\section{Acknowledgements}

The work was supported by the National Natural Science Foundation of China (No. 21705072), Henan Province Science and Technology Attack Plan Foundation (No. 172102310477), Colleges and Universities in Henan Province Key Science and Research Project (No. 17A150039), Natural Science Foundation of Liaoning Province (20180550016), and Shenyang Science and Technology Project (18-004-4-32).

\section{References}

1 Z. C. Liu, S. K. M. Nalluri and J. F. Stoddart, Chem. Soc. Rev., 2017, 41, 2459-2478.

2 G. Crini, S. Fourmentin, É. Fenyvesi, G. Torri, M. Fourmentin and N. Morin-Crini, Environ. Chem. Lett., 2018, 16, 13611375.

3 G. Parvari, O. Reany and E. Keinan, Applicable Properties of Cucurbiturils, Isr. J. Chem., 2011, 51, 646-663.

4 C. Yoo, H. M. Dodge and A. J. M. Miller, Chem. Commun., 2019, 55, 5047-5059.

5 R. Gramage-Doria, D. Armspach and D. Matt, Coord. Chem. Rev., 2013, 257, 776-816.

6 R. M. Kakhki, J. Inclusion Phenom. Macrocyclic Chem., 2013, 75, 11-22.

7 P. Řezanka, K. Navrátilová, M. Řezanka, V. Král and D. Sýkora, Enantioseparations, 2014, vol. 35, pp. 2701-2721.

8 B. Mokhtari, K. Pourabdollah and N. Dalali, Chromatographia, 2011, 73, 829-847.

9 T. Sun, N. N. Ji, M. L. Qi, Z. Tao and R. N. Fu, J. Chromatogr. A, 2014, 1343, 167-173.

10 T. Sun, M. L. Qi and R. N. Fu, J. Sep. Sci., 2015, 38, 821-824.

11 S. Shinkai, Tetrahedron, 1993, 49, 8933-8968.

12 H. J. Kim, M. H. Lee, L. Mutihac, J. Vicens and J. S. Kim, Chem. Soc. Rev., 2012, 41, 1173-1190.

13 T. Tuntulani, S. Poompradub, P. Thavornyutikarn, N. Jaiboon, V. Ruangpornvisuti, N. Chaichit, Z. Asfari and J. Vicens, Tetrahedron Lett., 2001, 42, 5541-5544.

14 G. Arena, A. Contino, F. G. Gulino, A. Magrì, D. Sciotto and R. Ungaro, Tetrahedron Lett., 2000, 41, 9327-9330.

15 H. Huang, D. M. Li, W. Wang, Y. C. Chen, K. Khan, S. Song and Y. S. Zheng, Org. Biomol. Chem., 2012, 10, 729-735.

16 P. Jose and S. Menon, Bioinorg. Chem. Appl., 2007, 2007, 116.
17 S. B. Nimse and T. Kim, Chem. Soc. Rev., 2013, 42, 366-386. 18 B. T. Zhao, C. B. Wang, S. J. Wu and B. X. Ye, Chin. J. Org. Chem., 2010, 30, 1212-1219.

19 G. Delahousse, R. Lavendomme, I. Jabin, V. Agasse and P. Cardinael, Curr. Org. Chem., 2015, 19, 2237-2249.

20 G. Horvat, V. Stilinović, T. Hrenar, B. Kaitner, L. Frkanec and V. Tomišić, Inorg. Chem., 2012, 51, 6264-6278.

21 A. M. Muscalu and T. Górecki, TrAC, Trends Anal. Chem., 2018, 106, 225-245.

22 S. Duong, N. Strobel, S. Buddhadasa, K. Stockham, M. Auldist, B. Wales, J. Orbell and M. Cran, Food Chem., 2016, 211, 570-576.

23 J. Zheng, C. Huang and S. Wang, J. Chromatogr. A, 2018, 1567, 185-190.

24 H. Potgieter, R. Bekker, A. Govender and E. Rohwer, J. Chromatogr. A, 2016, 1445, 118-125.

25 J. H. Park, H. J. Lim, Y. K. Lee, J. K. Park, B. E. Kim, J. J. Ryoo and K. Lee, J. High Resolut. Chromatogr., 1999, 22, 679-682.

26 Z. R. Zeng, N. Guan, X. H. Tang and X. R. Lu, Analyst, 2000, 125, 843-848.

27 J. H. Shi, Q. Q. Jia and S. X. Xu, Chromatographia, 2012, 75, 779-787.

28 G. Delahousse, V. Peulon-Agasse, J. Debray, M. Vaccaro, G. Cravotto, I. Jabin and P. Cardinael, J. Chromatogr. A, 2013, 1318, 207-216.

29 A. Mangia, A. Pochini, Ŕ. Ungaro and G. D. Andreetti, Anal. Lett., 1983, 16, 1027-1036.

30 L. F. Zhang, L. Chen, X. R. Lu, C. Y. Wu and Y. Y. Chen, J. Chromatogr. A, 1999, 840, 225-233.

31 X. D. Yu, H. Fang, L. Lin, H. M. Han and C. Y. Wu, Chromatographia, 2001, 53, 519-524.

32 J. L. Peng, T. Sun, L. Q. Wu, M. L. Qi and X. B. Huang, RSC Adv., 2017, 7, 45408-45415.

33 T. Sun, L. Tian, J. M. Li, M. L. Qi, R. N. Fu and X. B. Huang, J. Chromatogr. A, 2013, 1321, 109-118.

34 S. Shinkai, S. Mori, H. Koreishi, T. Tsubaki and O. Manabe, J. Am. Chem. Soc., 1986, 108, 2409-2416.

35 R. Nag, M. Vashishtha and C. P. Rao, ChemistrySelect, 2018, 3, 1248-1256.

36 L. Z. Qiao, K. Lu, M. L. Qi and R. N. Fu, J. Chromatogr. A, 2013, 1276, 112-119.

37 W. O. McReynolds, J. Chromatogr. Sci., 1970, 8, 685-691.

38 A. Berthod, E. Y. Zhou, K. Le and D. W. Armstrong, Anal. Chem., 1995, 67, 849-857.

39 T. Sun, H. Chen, X. G. Qiao, L. F. Ma, S. Q. Hu and X. M. Liu, RSC Adv., 2018, 8, 34102-34109.

40 M. A. Farajzadeh, N. Nouri and P. Khorram, Trends Anal. Chem., 2014, 55, 14-23.

41 M. M. Chen, G. H. Zhu, S. S. Wang, K. Z. Jiang, J. X. Xu, J. S. Liu and J. X. Jiang, J. Sep. Sci., 2018, 41, 440-448.

42 M. Torbati, A. Mohebbi, M. A. Farajzadeh and M. R. A. Mogaddam, Anal. Chim. Acta, 2018, 1032, 48-55.

43 S. S. Wang, Y. Y. Cheng, M. M. Chen and K. Z. Jiang, Eur. J. Mass Spectrom., 2018, 24, 337-343. 